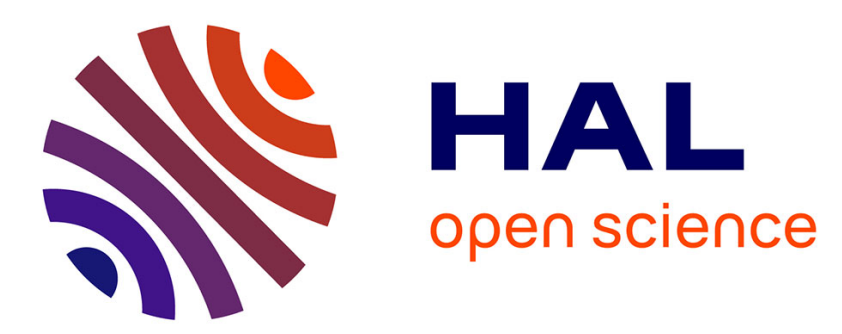

\title{
Scattering by polydisperse hard sticky spheres and the Porod-Auvray law for mixtures of large and small particles
}

\author{
J. Ravey, Stéphane Sauvage, M. Stebe
}

\section{- To cite this version:}

J. Ravey, Stéphane Sauvage, M. Stebe. Scattering by polydisperse hard sticky spheres and the PorodAuvray law for mixtures of large and small particles. Journal de Physique IV Proceedings, 1993, 03 (C8), pp.C8-141-C8-144. 10.1051/jp4:1993826 . jpa-00252257

\section{HAL Id: jpa-00252257 https://hal.science/jpa-00252257}

Submitted on 1 Jan 1993

HAL is a multi-disciplinary open access archive for the deposit and dissemination of scientific research documents, whether they are published or not. The documents may come from teaching and research institutions in France or abroad, or from public or private research centers.
L'archive ouverte pluridisciplinaire HAL, est destinée au dépôt et à la diffusion de documents scientifiques de niveau recherche, publiés ou non, émanant des établissements d'enseignement et de recherche français ou étrangers, des laboratoires publics ou privés. 


\title{
Scattering by polydisperse hard sticky spheres and the Porod-Auvray law for mixtures of large and small particles
}

\author{
J.C. RAVEY, S. SAUVAGE and M.J. STEBE \\ Laboratoire de Physico-Chimie des Colloïdes, Université de Nancy I, Faculté des Sciences, BP. 239, \\ 54506 Vandoeuvre les Nancy, France
}

\begin{abstract}
.
The structure of fluorinated gel-emulsions made of water globules dispersed into an (oil) fluorocarbon phase has been investigated by SANS, the water volume fraction being as large as $98 \%$. The oil continuous phase is a water swollen micellar phase, with a volume fraction of the micelles in the range of $10-40 \%$. The determination of the specific area of the water globules was performed by using the Porod-Auvray law. The validity of the approximation where the heterogeneous micellar phase is considered as being a homogeneous continuum is discussed by comparing to calculations for polydisperse hard-sticky spheres within the P.Y. approximation.
\end{abstract}

\section{EXPERIMENTAL}

By mixing oil, water and relatively hydrophobic nonionic surfactants, viscoelastic systems can be obtained for a certain range of temperature and of oil/surfactant ratio. From electron and optical microscope observations, it is seen that these "gels" are high internal phase ratio emulsions. Although large amounts of water can be incorporated, i.e. more than $97 \% \mathrm{v} / \mathrm{v}$, the continuous phase is an oil phase, as checked by simple electric conductivity measurements. As a matter of fact, $\mathrm{X}$ ray and small angle neutron scattering investigations have shown than this oil phase is a microemulsion-, or a water-swollen inverse micellar phase $(1,2)$, and the question arises whether these emulsion gels are stabilized by these smaller micellar particles. Although formed by hydrogenated compounds (3), they have also be found in fluorinated oil and surfactant systems. In fact these fluorinated gels may exhibit a perfect optical transparency for a defined oil/surfactant ratio, and are stable in a much larger range of water contents $(60-98 \% \mathrm{v} / \mathrm{v})$ as compared to the hydrogenated ones.

The first structural determinations have already be reported $(1,2)$ essentially by using SANS technique at the LLB, Saclay (PACE), and ILL Grenoble (D17). The spectra $I(q)$ (where $q$ is in the range $0.007-0.3$ $\mathrm{A}^{-1}$ ) are a superimposition of contributions from the large water globules (the emulsion droplets) and the smaller ones (water swollen micelles). Concerning the micelles, whose volume fraction in the fluorocarbon may be as large as $30-40 \%$, the detailed structures can be determined by using the contrast variation method (mixtures of $\mathrm{D}_{2} \mathrm{O}-\mathrm{H}_{2} \mathrm{O}$ as the water component), which generally gives rise to rather involved but informative spectra at larger $\mathrm{q}$. A few examples are presented in the previous preliminary papers $(1,2)$. As far as the emulsion is concerned, the mean radius of the large globules, or, more exactly, the specific area of their dispersion was evaluated from the smaller-q range of the spectra, using the Porod-law: with $\mathrm{D}_{2} \mathrm{O}$ or $\mathrm{H}_{2} \mathrm{O}$ for the water component, at these low q-values the spectra exhibit a $\mathrm{q}^{-4}$ dependance. Of course, in order to take into account the influence of the surfactant layer at the fuorocarbon-water interface, characterized by a 4-step scattering length density profile, the extended formulation due to Auvray (4) has to be used. Hence, the data have been interpreted by means of the following relation :

$$
I(q)=\frac{2 \pi S_{v^{\prime}} I_{S}(q)}{q^{4}}+(1-\phi) I_{m}(q)
$$


that is,as the sum of the contributions of two separate phases : the water-globules of specific area $S_{V}$ dispersed with a volume fraction $\Phi$, and the microemulsion phase, whose own scattering power is $\operatorname{I}_{\mathrm{m}}(q)$. Moreover, since the "spherical" micelles present a small size polydispersity, and in order to avoid more complicated calculations, $\mathrm{I}_{\mathrm{m}}(\mathrm{q})$ was approximated according to :

1b) $\quad I_{m}(q)=\sum_{i} x_{i} S_{i}(q) P_{i}(q), x$ is the number density, $P$ the form factor and $S$ the structure factor or the i-particle calculated for a volume fraction $\eta$, and a hard-sticky interparticle potential (5). In fact, for these particular systems, the micelles behave almost as hard spheres, and this is also probably the case for the larger water globules, given the stability of the systems which appear to be far from any phase separation or critical point.

Finally, the IS (q) function is a $\mathrm{q}^{2}$-series (4):

1c)

$$
I_{S}(q)=\left[\left(Q_{0}-Q_{w}\right]^{2}+q^{2} f_{1}+\ldots\right.
$$

where the first term is the difference of the scattering length densities for the two media on each side of the membranes, that is water and oil (fluorocarbon). The set of equations 1 are simple approximations used for convenient fitting procedures of experimental data. Their validity had been assessed by the coherence of the results from large set of data in most various experimental conditions. For limited polydispersity level $(\sigma / \mathrm{D}<0.2, \sigma$ and $\mathrm{D}$ being the standard deviation and $\mathrm{D}$ the mean value of the particle diameter, and $\phi<0.4$ ), eq. $1 \mathrm{~b}$ is quite satisfactory as it has been checked from exact polydisperse hard sphere calculations. But what we want to point out in this short paper are the conditions of applicability of eq. la for the smaller q-part of the spectra.
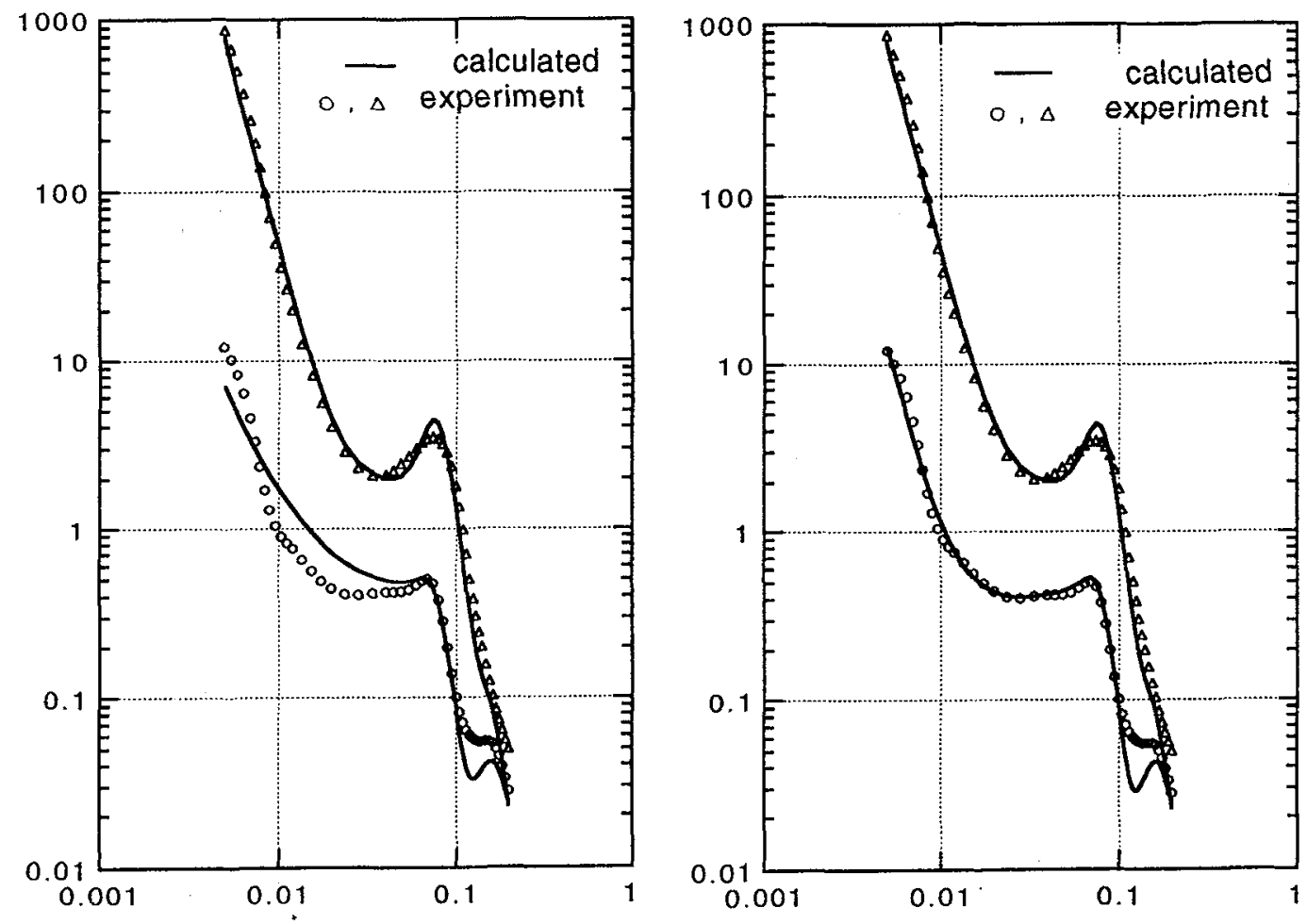

Figure 1 Experimental SANS spectra $\mathrm{I}(\mathrm{q})\left(\mathrm{O}:\right.$ water $\left.27 \% \mathrm{H}_{2} \mathrm{O}, \Delta=\mathrm{H}_{2} \mathrm{O}\right)$. Lines are fits for two $Q$ values of the "sulvent" used in Porud-Auvray equation ( $a$ : pure fluorucarbon, $b$ : mean value uf the micellar phase). 

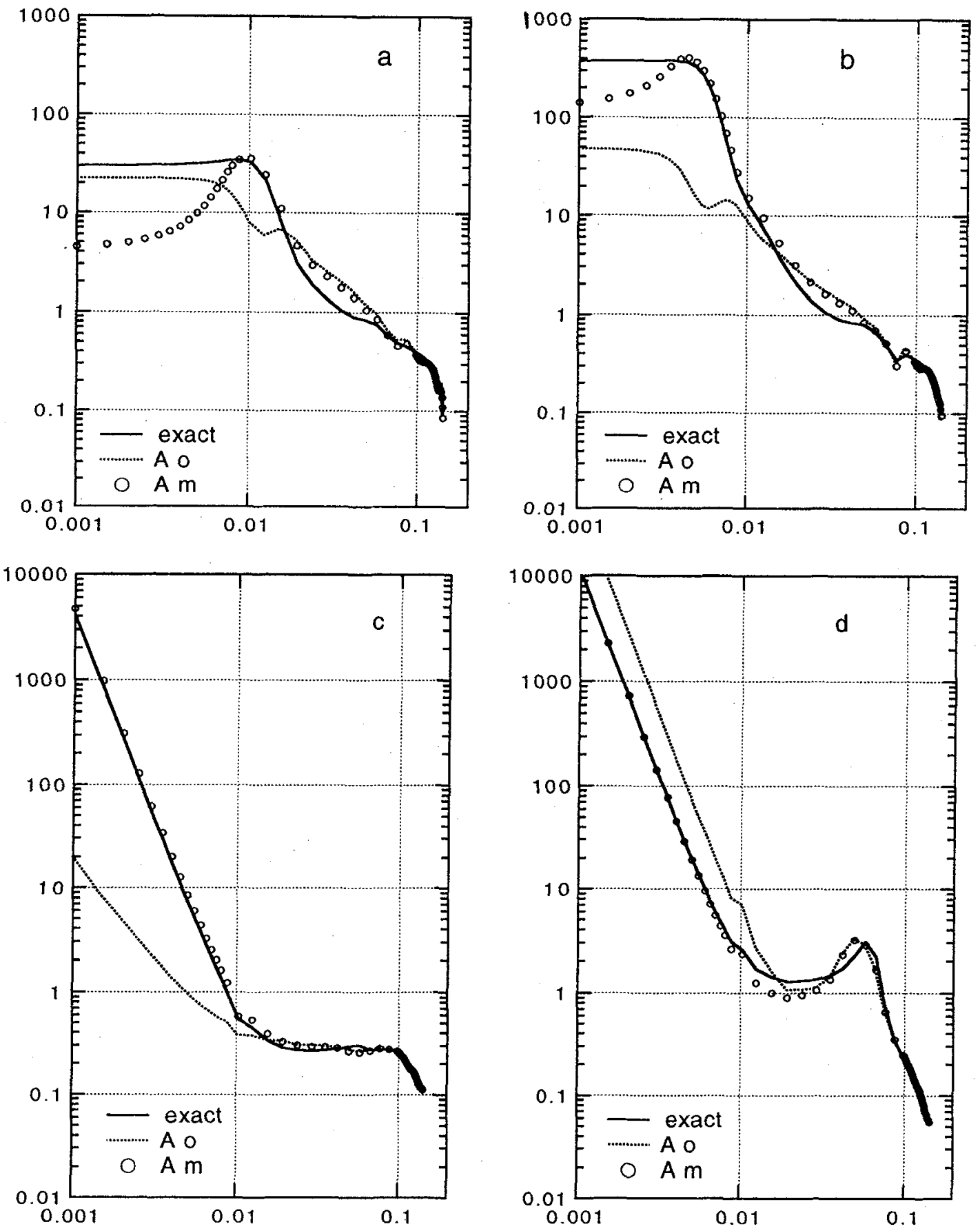

Figure 2 Calculated intensity scattered by pulydisperse spherical shells $(a, b, c)$ and spheres (d). The size distributiun is bimudal $(\sigma / D=0,2)$, $D_{1}=100 \mathrm{~A}, D_{z}=500 \mathrm{~A}(\mathrm{a}), 1000 \mathrm{~A}(\mathrm{~b}), 10000 \mathrm{~A}(\mathrm{c}, \mathrm{d})$. Lines are exact P.Y. resulis. $A_{t}$ and $A_{m}$ are approximations ( see text). 
When the water component is $\mathrm{D}_{2} \mathrm{O}$ or $\mathrm{H}_{2} \mathrm{O}$, slightly different values for mean radius of the globules $\mathrm{R}=3 \phi / \mathrm{S}_{\mathrm{V}}$ are obtained, typically 5 versus 9 microns. Although not fully satisfactory, this difference could be ascribed to a difference in the state of dispersion of the emulsions; however it has been found systematically whatevever the surfactant and water contents. Things seem quite wrong if the scattering length density of the water is made identical to that of the fluorocarbon $\left(27 \% \mathrm{D}_{2} \mathrm{O}\right.$ in the $\mathrm{D}_{2} \mathrm{O} / \mathrm{H}_{2} \mathrm{O}$ mixture). This can be seen in figure $1 \mathrm{a}$ : open cercles and triangles correspond respectively to this particular isotope mixture and to $\mathrm{H}_{2} \mathrm{O}$. Full lines represent calculated values according to eq. la-c with $\mathrm{Q}_{0}$ equal to the scattering length density of pure fluorocarbon. In fact this discrepancy has to be related to the surfactant content of the micellar phase : experiments at various compositions show that the larger this content the larger the discrepancy. Hence $Q_{0}$ has to be changed. If it is taken equal to the mean scattering of the whole micellar phase, eq. $1 \mathrm{a}-\mathrm{c}$ give the full lines in the 1-b figure ; besides, from these rather good fits the same value of $R(5 \mu)$ is obtained, irrespective of the isotopic composition of water.

\section{THEORETICAL AND DISCUSSION}

A justification of eqs. 1a-c may be carried out by refering to the exact calculation of bimodal polydisperse spherical particles.

$$
I(q)=\sum_{i, j} \sqrt{x_{i} x_{j}} S_{i j}(q) F_{i}(q) F_{j}(q)
$$

$S_{i j}$ are the partial structure factors, and $F_{i}$ the amplitude scattered by the i-particle. Calculations have be performed in the case of hard slightly sticky spheres, by using the equations derived by Robertus (6). The bimodal distributions were a superimposition of two Shulz size distributions, with the two mean diameters $\mathrm{D}_{1}=100 \mathrm{~A}$ and $\mathrm{D}_{2}=500 \mathrm{~A}$ (figure $2 \mathrm{a}$ ), $1000 \mathrm{~A}$ (fig. $2 \mathrm{~b}$ ), 10000A (fig. $2 \mathrm{c}, 2 \mathrm{~d}$ ) and $\sigma / \mathrm{D}=0.2$. Fig. $2 d$ refers to homogeneous spheres while fig. $2 a-b-c$ refer to spherical shells with a membrane thickness of $20 \mathrm{~A}$. Full lines are exact calculations. In relation to eq. 1 two approximations are proposed :

3a)

$$
\mathrm{I}(\mathrm{q})=\phi<\mathrm{S}_{1}(\mathrm{q}) \mathrm{F}_{\mathrm{m}, 1}^{2}(\mathrm{q})>+(1-\phi)<\mathrm{S}_{2}(\mathrm{q}) \mathrm{F}_{\mathrm{o}, 2}^{2}(\mathrm{q})>\boldsymbol{\eta}
$$

(approximation $\mathrm{A}_{\mathrm{m}}$ )

3b)

$$
\mathrm{I}(\mathrm{q})=\phi<\mathrm{S}_{1}(\mathrm{q}) \mathrm{F}_{0,1}^{2}(\mathrm{q})>+(1-\phi)<\mathrm{S}_{2}(\mathrm{q}) \mathrm{F}_{\mathrm{o}, 2}^{2}(\mathrm{q})>\eta
$$

(approximation $\mathrm{A}_{0}$ )

$S_{1}$ are the structure factors for large particles of volume fraction $\phi=0.3$ and $S_{2}$ those for the smaller particles of volume fraction $\eta=0.5$. For $D_{2} \ll D_{1}$, eq. 3 are equavalent to eq. 1 for the $q$-range of the present investigation. $F^{2} \mathrm{~m}, \mathrm{i}$ is the intensity scattered by a sphere/shell $\mathrm{i}$ when the "solvent" scattering length density is taken equal to the mean value of that of the "continuous phase" of the small particles. And $\mathrm{F}^{2} \mathrm{O}, \mathrm{i}$ is the intensity scattered when this scattering length density is that of the pure solvent (equal to zero in the calculations). In figure 2 , full lines are for exact calculations (eq.2), open cercles and dotted lines for $A_{m}$ or $A_{0}$ approximations. Fig. $2 a$ to $2 c$ show the influence of the ratio $D_{1} / D_{2}$ of diameters of spherical shells. Clearly, exact and $A_{m}$ approximation results become very similar when $D_{1} / D_{2}>10$, at least in the experimental $q$-range. And, obviously, the discrepancy between exact and $\mathrm{A}_{0}$ approximation is quite enhanced when scatterers are vesicles (spherical shells).

To conclude, the comparison of theoretical (fig. 2c-d) and experimental/fitted (fig. 1-b) spectra clearly confirm the validity of the simple relations 1 . However, this can be true only on the condition that, when using Porod-Auvray equation, the scattering length densities of the media at each side of the interfaces must be taken equal to the mean density of the surrounding phases when inhomogeneous.

\section{REFERENCES}

[1] Ravey J.C., Stebe M.J. (1989) Physica B:394 156-157

[2] Ravey J.C \& Stebe M.J. (1990) Progress in Coll. \& Polymer Sci. 82:218-228

[3] Solans C., Dominguez J.G., Parra J.L., Heuser J., Friberg S.E. (1988) Colloïd Polym. Sci 266:570

[4] Auvray L., Cotton J.P., Ober R., Taupin C. (1984) J. Physique 45:913

[5] Regnaut C., Ravey J.C. (1989) J. Chem. Phys. 91:1211

[6] Robertus C.,W.H. Philipse, Joosten J.G.H. \& Levine Y.K. (1989) J. Chem. Phys. 90(8) 4482 